\title{
GROWING UP AND NURTURING A RURAL COMMUNITY: AN INTERVIEW WITH HOPE ROBSON, BISHOP'S CASTLE, UK
}

\author{
"If I could apply my time to help people when I know that I can help them and
that it could work - why wouldn't I?" \\ Hope Robson
}

Interview by Keith Whiddon

Keith: Tell me a little about your background Hope.

Hope: I grew up in a small rural town in Shropshire, UK. It's very much a stronghold community here in the town where I live. It gave me the values and beliefs that I have now and that has allowed me to do all the work I do.

As well as growing up in a small rural community I also have another side to my background, which is a more nomadic way of life - travelling around to different festivals, with different types of cultures, creative arts and music - with lots of different things to offer.

So when I grew up, I was able to have a look at different areas of life; different lifestyles and different ways of people living. My background came with a lot of highs and amazing experiences - ones that l'll cherish for a lifetime. But also, I have a lot of understanding of the other parts of life that might not necessarily be so positive. My background really is about human connection and experiencing community in every sense. So I really enjoy having the background that I do. I think I understand culture quite well from it and I'm able to really understand and empathise with a lot of people, because l've experienced quite a few things - and quite a lot of these things I come across in my everyday life and in my career.

Keith: What was that like to grow up in Bishop's Castle?

Hope: I really enjoyed growing up in Bishop's Castle. Not many people would think that you'd enjoy being out in such a rural place, but that's what made it special. We always played out in the countryside. There was a big group of us all around the same age and we all got on. Everyone's family sort of felt like your family. You knew everyone's mums and sisters and brothers and aunties and uncles - you'd stay at different people's houses. There'd be a lot of festivals and things that we could get involved with.

I personally didn't have much difficulty with coming out of the rural headspace and rural scene because of the nature of the other side of my background, which has been a bit nomadic. I was well travelled, so being in a rural town never really fazed me as I got to experience all these other places around the UK and abroad. But I know that for a lot of the people I grew up with, travel was a big thing and not being able to utilise the resources that the UK can offer, because of their inability to be able to travel.

We don't really have much resource given to us here in Bishop's Castle. When I grew up it was very limited with the amount of opportunity that you could get as a youth. There weren't really any youth clubs. There weren't 
any of the things you could get in big towns, where you get quite a lot of leisure activities tailored all around. We had a couple of things to keep us going - it was only a few things and as a community, we really had to fight for those things.

Growing up here was lovely because your friends mattered. The connection you made with your friends really mattered, because they were all you had. You couldn't just go and make a new group of friends - there wasn't a new group of friends to make. So you always had to use conflict resolution. You always had to understand yourself a lot more - you always had reflections around you. Also, everyone knows everybody here, so you had to be good growing up here in respect of the reputation of your family, because everyone knows everybody here. You want to do well - you want to do well for your family - you want to be seen as a good person here. Reputation means a lot in the small town that we live in because you're here for so long.

Keith: What did you study after school? Why was that your chosen course?

Hope: So, when I was in school, I didn't do very well. I have dyslexia, which meant that it was really difficult for me to be able to apply myself correctly through my GCSE studies, which is what we did in secondary school. After I left school, I didn't have enough GCSEs to do the original things that l'd like to do. I would have liked to have done more arts and psychology and try to do art therapy, because at the time, I was very much into that. But I didn't have enough qualifications at that point to be able to. So luckily, my path actually was led down to Health and Social Care, as a vocational study, BTEC level 3 extended diploma - and I really enjoyed doing that. It was definitely something that was made for me in the way of being a good experience and getting me to where I needed to be in life.

So the BTEC level 3 Health and Social Care gave me 450 hours of volunteered vocational study, which meant I did placements in a lot of different sectors that focused on different areas of health and social care: from homelessness; to youth referral within homelessness; working with nursery children and also in a care home with people with learning difficulties. I also did an extensive amount of course work. I really enjoyed doing Health and Social Care - I learned so much more about culture, about diversity, about a safeguarding people, how to do the right thing, understanding a lot more about connection, dignity and care.

I also did a Complimentary Therapy course VCTC level 3, because I believe in looking at people holistically. When I was in college, I realised that there was a lot to health and social care, not just medical care and not just basic care standards. I realised that there's a holistic way of looking at people. My complementary therapy focuses a lot on that aspect. So I do massage, aroma therapy, reflexology, with the hope to progress with other therapies that can help within the holistic model of health.

I then went on to university. I studied a Foundation Degree in Health and Social Care. Because of my dyslexia, I didn't feel like I was able enough to go off to a bigger university lecture hall, so I did a foundation degree, which was also another vocational study, where I was able to do two days of placement in a nurture school for emotionally challenged children and some who were on the autistic spectrum. That was really good. I really got to see what it was like to use holistic teaching and realistic education for children that were emotionally challenged and the difference that it made these children to have this therapeutic care and nurture given to them and how much that allowed for them to make positive future pathways for themselves.

Keith: You've made your home in Bishop's Castle when many young people your age have moved away. What made you want to stay here?

Hope: So with my background and growing up in Bishop's Castle and also knowing lots more about cultures in different ways and lifestyles, I immersed myself quite deeply into the connections I have with people - into spaces and into environments. I've never really wanted to go to a bigger place because I've already been to quite a few big places. I've already been to festivals. I've already been to mass gatherings. I don't need to go into a place that has a lot of resources like a city or a big town. I like living small and local in a stronghold community. I enjoy having a safe 
space on this earth where I can come and I know the people, they know me - where they've known me since I was little. I'm safe here. I don't enjoy animosity. I don't enjoy the loneliness of a city. I think that that there's a lack of connection there. I'm quite a tribal person in that sense. I really like the fact that Bishop's Castle has massive sense of tribe. Also, I personally couldn't leave this place because I believe that there's a lot of work to be done here for the next generations that come after me.

I believe in this town and I believe in what it can offer people. It's so creative, it's so flamboyant! It has so many positive things to it. So when I look at staying in Bishop's Castle, I want to create a positive construct for the people in this town, so that they can live a good quality of life - something that l'd find very hard to do in a bigger place. I don't think in a bigger place, my ideas will be listened to, or I would be respected as much as I am here, or that they would get as much motion as what they do here. Because l'm in a small town, I'm able to really apply myself here and things are able to be seen and heard - and I feel very supported. I realised that most of my friends that go away come back later and I don't want to be one of those people to leave this place and come back few years later to watch it just get more derelict, more buildings not being used, less young people, more older people, less carers. I don't want to come back to my town and see it being is deteriorated because nobody's put in the effort to keep it strong. So I don't leave and I haven't decided to leave because I want to make this town strong.

Keith: You are now a Social Prescribing Advisor - can you explain what Social Prescribing? What does your job entail?

Hope: So after doing uni I understood a lot more about the environment and determinants of health, and how much determinants of health impact us. This might be psychological, sociological or biological. I realised that in our society, there are lots of people that are going through lots of different things and each one has a determinant of health that they're going through - and it could really change their life in ways that they wouldn't or might be expecting.

I was able to acquire a job as a Social Prescribing Advisor in Shropshire. What we do is we give people time to talk. We offer them action plan, a type of non-clinical prescription that gets them out and about into their community, as well as into different services. I can signpost people to different services, or I can refer them into quality-assured, signed-up interventions. So this might be cookery courses, music clubs, exercise on referral - there are lots of different avenues that I can refer people to.

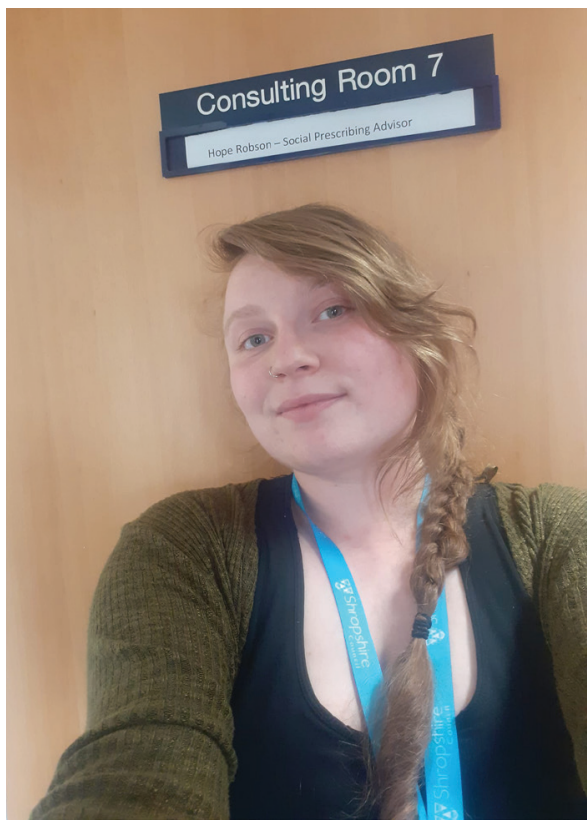

Figure I. HopeRobson, Social Prescribing Advisor. Source: Hope Robson

So, to give you an example, a young adult who has asthma has an inhaler and is coming to the pharmacy too often to get a prescription. They have been having panic attacks and anxiety attacks and are using the inhaler. They didn't realise that asthma attacks and anxiety attacks are two different things. Social prescribing can support them through this understanding of that determinant of health, which was that they have this biological condition of asthma and they have prescription medication to be able to help with that, but they are abusing their prescription medication and using it for another type of concern; the other concern, anxiety, can be worked on and aided. A doctor can refer them to social prescribing so that they can get support. We could speak about anxiety and 
different services and different pathways that they could be referred to, that would maybe help them understand their anxiety better.

After setting up a pathway, a few months of talking, and a few interventions with the counsellor, a few workshop style things in the community or on the internet, a meditation app, etc., this young adult may start to understand their anxiety a lot more and feel supported through this transition.

In a good case they won't need their inhaler as they now understand the difference between a panic attack and asthma attack and they understand themselves better. We could then work on how we get them from being anxious and not being able to do things day to day, to how to progress into doing something that they are interested in. We'd hope to build their confidence back by understanding their conditions more and be able to make their future pathways. It is about self-empowerment and positive choices.

So that's what Social Prescribing is really about. It's being able to pick up people that have determinants of health and trying to address what their needs might be to make sure that they don't have future health concerns, when we could have done some early intervention, to be able to help them through these determinants of health.

Keith: You have been working with New Zealand year 3 nursing students for the past 2 years using the 'CHASE model'. How was this experience?

Hope: I've been working with New Zealand student nurses for a few years now and it's been a really good experience. Being a Health and Social Care practitioner, I really enjoy what the nurses have to offer. Also being part of the holistic health ethos and understanding that there's a lot more to health than just the medicine and just looking at people biologically, the nurse's project gives me a sense of inspiration. I really enjoy what they look at, how they look at it and why they look at it; why health comes about and how they can help with people's health. I really enjoy the fact that they look at the geographical area and look at lots of people within that - not just one or two people, because I feel that health is also a societal thing. Within that holistic ethos it's everybody's business to have a healthy society and everybody has a role to play in having a healthy society. There are a lot of factors that make a healthy society and lots of factors that makes a healthy person.

So with the nurses and what they do, I can see how they're trying to empower people, to show them that they have a role in health and that they can make their health better as well as their communities. It also helps someone like me that lives in a rural place where we don't have much resource and we don't have many people looking in on us, to have the nurses look at our town and give us statistics and evidence to back our ideas up. We're able to have credited information which we can apply and help us with our future development projects. So being part of this project has meant so much to me. I've been able to get myself heard and listened to. It's just been such a pleasure working alongside a group of younger adults on the other side of the world.

Keith: You're applying your expertise to help build a Community Hub for Bishop's Castle. What gave you the idea for this?

Hope: So, I have started to try to build a Community Hub in Bishop's Castle - and when I say Community Hub and Bishop's castle, I'm not just talking about a place where you go and it's a nice area - you know, like a typical Community Hub. I'm talking about something that's quite diverse in the way that it approaches people. I want everybody to feel accepted, welcomed and respected when they come into the Hub.

So I decided to come up with the Hub idea because I have worked in so many different sectors, so many different job roles and so many different areas each with a different ethos: the nurture school and how they work to educate; the homeless shelter and how they help with psychological and physiological needs; the youth referral and how they work to try and get these kids back into understanding how to live independently to the nursery, and understanding how nursery kids are taught in forest schools and things like that. 
All of my experiences from the age of 16 to my age now, which is 23 , I've looked at different services and realised that there's no joined-up situations and I think that's really the very basic mono level. I want to try and make a service that's going to harness the community's talents and potential, in all sense - not just one type of way of being or one type of ethos. I would like to be able to create a hub that's going to expand the community's talents, entrepreneurial skill and skill-set, as well as connect them, as well as highlight all the different projects, and different head-spaces and ideas that the community do have, as well as give traffic to the ones that already exist. All the different projects already exist - I want to be able to make them stronger. I think creating the Community Hub will do that.

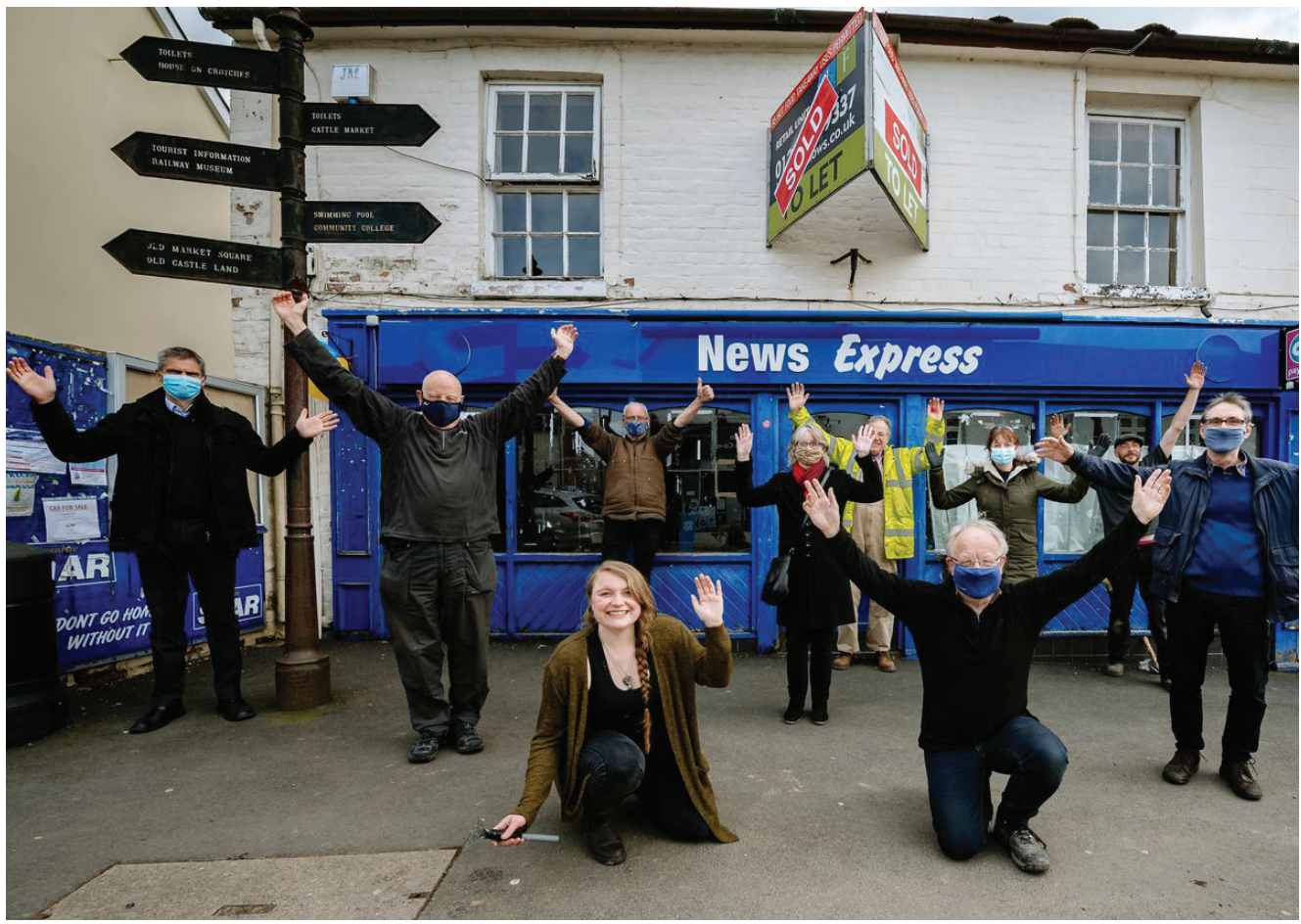

Figure 2. Community Hub Project. Source: Hope Robson

Keith: Can you describe what the Hub might look like?

Hope: The Hub we want is a facility where you'd 'walk in, talk to us and we connect you into your community'. We'd like it to be quite central hub, then you come in and we have lots of different things to offer; we call them micro-hubs in the community - already established parts of the community that are happening, that people can get involved with. And if there aren't already established parts, micro-hubs that they enjoy then creating micro-hubs that people enjoy, so that we can keep people's talents alive. So that we can keep people merging, connecting, learning and passing down skills. So these micro-hubs will range from all different things, from construction to art and design, to events management, and helping with events management. 


\section{Walk in $\Rightarrow$ Talk to us $\Rightarrow$ Connect into your community!}
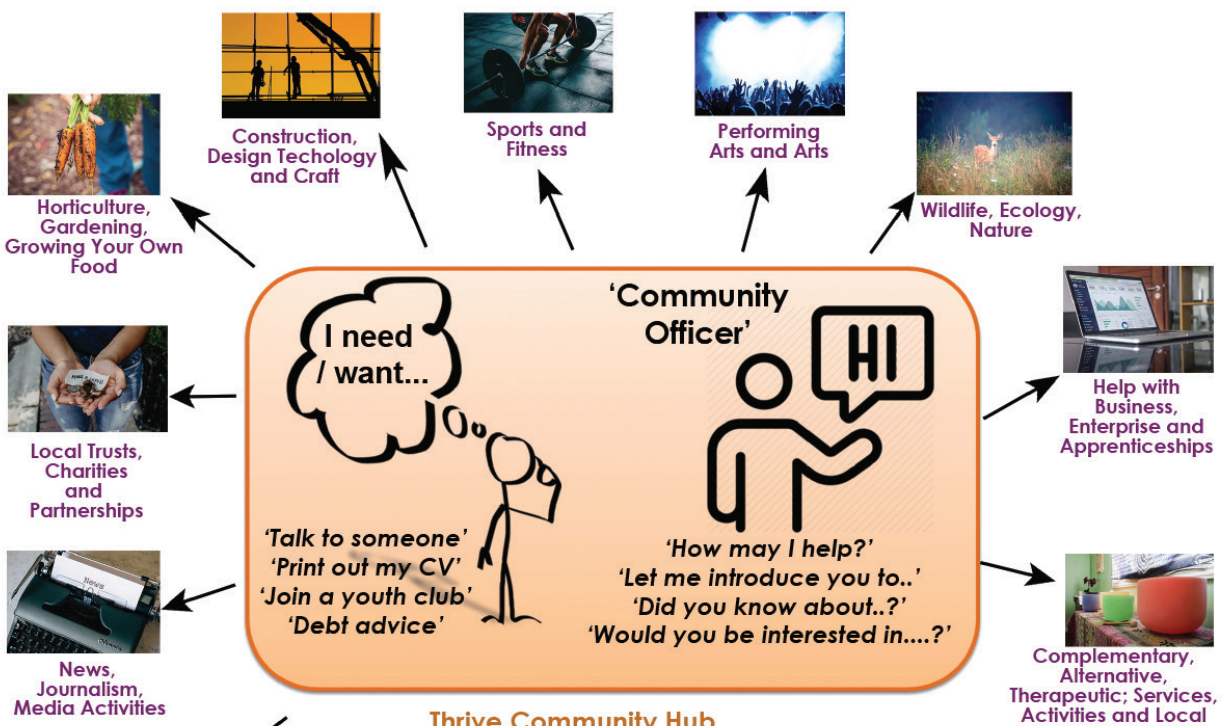

Media Activities

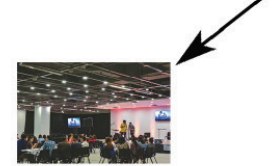

Thrive Community Hub

Activities and Local

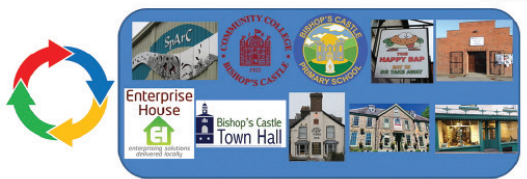

Helping Events

Management

Exłernal Facilities

Figure 3. Hub Diagram. Source: Hope Robson

Keith: What drives you to want to help others like you do?

Hope: What drives me is the sense of achievement that I get when I watch, see, feel, or hear that the intervention that l've been able to give through my understanding has made a positive impact on one person, or two people or a family or community. I think the real sense of why I want to help is because I want to make people feel like life's worth living - that they can have a good quality of life - that there are little tips and secrets in life that can get you through. I've experienced a lot in my life, and I can understand and empathise with a lot of things. This makes me want to be able to help people. If I can help them, why wouldn't I? If I could apply my time to help people when I know that I can help them and that it could work why wouldn't I? That's the question. I always ask, 'why wouldn't you just do that'?

I think I'm quite a selfless person when it comes to something like that. If it was up to me, I would just be doing all of this behind the scenes, without anybody really knowing that is me doing it - because it's not about me - it's about the people that I'm helping. But luckily for me, I actually have people around me that respect me and want 
to hear about my ideas and that want to interview me and listen to what I have to say. So that most of the stuff that I do isn't just behind the scenes, or no one knows that it's me. But yeah, is a quite a daunting experience and I know that I'm quite a big role model for a lot of people in my area. I just want to be able to give them the best quality of life that I can and I hope that the Hub idea can achieve that.

Bishop's Castle breeds people with big hearts and it breeds people with big minds. It breeds people that have amazing creative abilities - and l'd never want that to die.

Hope Robson is a Social Prescribing Advisor with Shropshire Council. She grew up and still lives in Bishop's Castle, a small and remote town in the Shropshire Hills, UK. Hope studied as a Health and Social Care practitioner and has a strong desire to improve the health and wellbeing of her community.

Correspondence to: Hope Robson. Email: Hope.Communityl0I@outlook.com 